AJIS FEATURED THEME:

\title{
THE INFORMATION SYSTEMS DISCIPLINE IN AUSTRALIAN UNIVERSITIES
}

\author{
Editor:
}

\section{Professor Guy Gable}

\author{
IT Professional Services Research Program \\ Faculty of Information Technology \\ Queensland University of Technology \\ Brisbane, Queensland, Australia \\ email: g.gable@qut.edu.au
}

This AJIS Featured Theme comprises 12 research papers that present a portrait of The Information Systems Academic Discipline in Australian Universities. This Australian study is part of a broader study - 'The State of the Information Systems Academic Discipline in Pacific Asia', the results of which are forthcoming in a similarly titled special issue of Communications of the AIS.

Drawing on Whitley's Theory of Scientific Change, the papers analyse the degree of 'professionalisation' of the Information Systems Discipline, the overarching research question being "To what extent is Information Systems a distinct and mature discipline in Australia?”

All papers in the special edition have been subject to a three-tier peer review process: Each paper has been initially reviewed by the AJIS editors, feedback has been provided to the authors and revisions made. Then, each paper has been sent to a local (state-based) IS expert for review; the results of this review being conveyed anonymously to the author of the paper, and consequential revisions made by the authors. Finally, all papers considered for the special edition were sent to two further IS experts (international) for global review, with feedback from the reviewers again being forwarded to authors for revision of their papers.

Professor Gable Chairs the IT Professional Services Research Program, Faculty of Information Technology, Queensland University of Technology http://sky.fit.qut.edu.au/ gable/. His PhD is from University of Bradford and MBA from Ivey Business School. He is Senior Editor Journal of Strategic Information Systems, Associate Editor MISQ, and on the Editorial Boards of Journal of the AIS, Information Systems Frontiers, and Australasian Journal of Information Systems. Key research interests include IT Professional Services, IT Research Methods, Enterprise Systems, and IT Evaluation. Career emphasis is on research collaboration with industry and the professions - Chief Investigator $(\$ 3.0 \mathrm{M}+)$ on grants with Accenture, SAP, CUSC, Institute of Management Consultants, and Queensland Treasury. He has

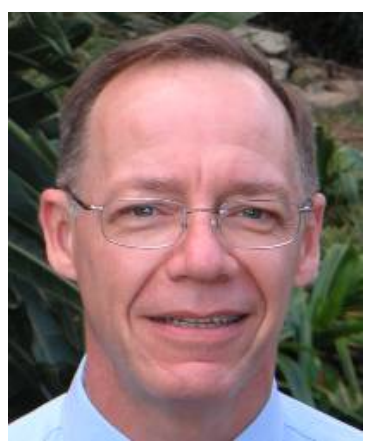
published $>100$ refereed journal articles, conference papers and books. 
